\title{
DE BENOEMING VAN EEN GROOTOPPERHOOFD DER BOSCHNEGERS
}

DOOR

\section{JUNKER}

$\mathrm{Nu}$ eens aanzwellend tot het geraas van bulderende watervallen en daarna wegstervend tot het ruischen van het oerwoud wanneer de passaat krachtig door de kroonen der boomreuzen strijkt, golfde het geluid van talrijke trommen tusschen de hutten van het dorp Sidomopo, de woonplaats van den Granman der Saramaccanen op en neer. Er was, zooals bij de dansen, geen rhythme te bespeuren, slechts schrik aanjagende wanklanken doorgalmden de lucht en dit lag ook in de bedoeling; vele het dorp belagende booze geesten moesten door het spektakel op de vlucht worden gedreven. Om aan dezen het binnendringen van het dorp te beletten, waren ook de fetischen die de toegangen bewaakten, de asanpau 1), versterkt. Voor het nemen van al deze maatregelen waren goede redenen aanwezig. Jankosoe, de reeds sedert weken overleden Granman, zou weldra, zooals dit reeds ontelbare malen had plaats gehad, wederom opgenomen en ondervraagd worden. De doode had wel als oorzaak van zijn overlijden den Koenoe, den op alle Grootopperhoofden van den onderstam der Matjau rustenden vloek genoemd en ook op talrijke vragen aangaande aangelegenheden van den stam geantwoord, echter beslist geweigerd een opvolger aan te wijzen.

Omdat het voor den lezer onmogelijk zal zijn zich zonder eenigen uitleg een goed begrip van de hierna verhaald wordende gebeurtenissen te kunnen vormen, zal een beknopte vermelding

1) Asanpau wordt de soort eerepoort genoemd die de toegangen van iedere heidensche nederzetting afsluit. Op twee in den grond gestoken stokken rust een met een gespleten blad der Maripapalm versierde derde stok. Ieder die het dorp betreedt moet onder den laatsten door loopen. Bij de verticale stokken zijn fetischen geplaatst en ook in bladeren is geestenmacht gebracht. Deze neutraliseeren alle booze voornemens en jagen de booze geesten weer in het bosch terug. 
van de voorstellingen welke de Boschnegers er omtrent den dood op na houden en van de naleving der gebruiken bij sterfgevallen, op haar plaats zijn.

Wanneer een mensch sterft verlaat de Kra of ziel het lichaam, doch wordt van dit oogenblik af door een geest vervangen, Jorka genoemd. Deze laatste blijft aan het lichaam en al zijn onderdeelen gebonden. Eerst op het tijdstip van de begrafenis verlaat hij dit, om, wanneer hij een goed leven heeft geleid, de reis naar de verblijfplaats der dooden aan te vangen; komt een Boschneger in den vreemde te overlijden, dan wordt hem een haarlok, alsmede van rechter duim en grooten teen de nagel afgeknipt. Deze overblijfselen van den doode verlaten de Jorka niet, zij worden naar zijn geboorteplaats, waar zijn mingo of navelstreng werd begraven, overgebracht en aldaar in een miniatuur lijkkist geborgen. Daarna wordt deze opgenomen en wordt de inhoud op dezelfde wijze ondervraagd als dit met een lijk plaats heeft.

Zelfs met het lijkwater, dat van de in ontbinding verkeerende lijken van Boschnegers afdruipt, blijft de Jorka verbonden. Dit blijkt uit de volgende overlevering. De Matjau negers wilden het Grootopperhoofd Akrosi uit den weg ruimen, teneinde hun candidaat voor de waardigheid op den zetel te kunnen brengen. Te Dangogo aan den Pikien Rio lag reeds sedert een week het lijk van een Boschneger onbegraven, waarvan het middel tot den moord, het afdruipende, de lucht verpestende vocht, werd verzameld en daarna onder bezwering en tooverformules in de rivier gestort. Aan de Jorka van het lijkwater werd opgedragen de rivier af te drijven en te Kapoaston, een rots in het water, waarop de Granman gewoon was zijn siësta te houden, den laatste te dooden. Volgens de Boschnegers kwijtte zich de Jorka van haar taak; Akrosi werd tegen een avond dood op de rots gevonden.

Ook de maatregelen die getroffen moeten worden wanneer een Boschneger per ongeluk om het leven komt, of vermoord wordt, illustreeren duidelijk de voorstelling der onafscheidbaarheid van geest en lichaam. Geloofd wordt, dat de Jorka van een mensch die tegen zijn wil plotseling van het leven wordt beroofd, onverzoenlijk en steeds op wraakneming belust, een groot gevaar voor de geheele samenleving oplevert. Wordt het lijk van een verongelukten of vermoorden Boschneger gevonden, dan ontvliedt ieder de plaats des onheils en worden onmiddellijk de adepten der Obia (beschermend toovermiddel), dressie genaamd, gewaarschuwd. Zij alleen zijn uitgerust met de afweermiddelen tegen de aanvallen van de kwaadaardige Jorka. Door bezwering wordt 
deze aan het doode lichaam geklonken en dit wordt daarna door de ingewijden van de Obia begraven. Op het graf wordt een haan geslacht, de versche aarde met het bloed daarvan besprenkeld en het doode dier ten slotte op den toegangsweg tot het graf achter gelaten. Met deze handelingen is aan de Jorka alle vrijheid van beweging ontnomen, levert zij voor de menschen geen gevaar meer op. Niettegenstaande al deze voorzorgsmaatregelen, waagt het geen Boschneger ooit de plaats weer te betreden.

Komt een Boschneger op gewone wijze te overlijden, dan is de zaak veel eenvoudiger. Ingewikkelder is deze alleen bij den stam der Aucaners, omdat bij dezen als doodsoorzaak bijna altijd wisi - misdaad door vergif of met behulp van bovenzinnelijke machten - wordt verondersteld. Hierdoor komen de met den dood van een individu verbonden omstandigheden in het bereik der jurisdictie van den oppersten fetisch der Aucaners, de Grantata of Gwanggwella. Vroeger werden de personen die den dood van een medemensch veroorzaakt hadden verbrand, thans blijven dezen gebrandmerkt leven; bij hun dood vervallen al hun eigendommen aan de Grantata en hun lijken worden niet begraven, doch op een daarvoor bestemde plaats in het bosch geworpen.

Het verhaal dat hier gegeven wordt speelt echter bij de Saramaccanen en het bij hen gehuldigde begrip van den Koenoe maakt, zooals gezegd, de zaak eenvoudig. De doode blijft zoolang hij niet begraven is dezelfde persoon die hij in leven is geweest. Was hij een persoon met groote ervaring, dan wil men zoo lang mogelijk van deze profiteeren, door hem of haar telkens te ondervragen. Omdat de doode zich niet meer bewegen kan, wordt hij opgenomen en naar de plaats der ondervraging gedragen. Dit heeft op de volgende wijze plaats: het in witte doeken gewikkelde lijk wordt stevig op een met pimbadotti - de magische witte porceleinaarde - geschilderde plank bevestigd. Deze wordt daarna door twee Boschnegers op de hoofden geplaatst en van de hut, waarin het lijk op een stellage van stokken ligt, naar de plaats der ondervraging gedragen, waar op eenigen afstand van de persoon die het lijk zal ondervragen halt wordt gehouden. Door tallooze vragen te stellen wordt allereerst de oorzaak van het overlijden vastgesteld. De voorste Boschneger, die geacht wordt het medium van den geest des dooden te zijn, antwoordt op de vragen door knikken met het hoofd wanneer het antwoord bevestigend luidt en schudt dit bij wijze van ontkenning. Teneinde vast te stellen of de doode de waarheid heeft gesproken, wordt de volgende proef genomen: voordat de dragers met het 
lijk zijn aangekomen wordt door den ondervrager aan twee Boschnegers elk een blad of takje van twee verschillende planten gegeven en worden deze op eenigen afstand rechts en links van hem geplaatst. Nadat een vraag gesteld en beantwoord is, noodigt de meestal oudere neger die de vragen stelt den doode uit omtrent de waarheid van zijn beweren te getuigen. De dragers zetten zich daarop in beweging en loopen naar een van de negers aan wie de bladeren of takjes zijn gegeven. Deze laat de laatste zien en wanneer het blad dat vertoond wordt afkomstig is van de in de Kolonie algemeen bekende sangrafoe, een Zingiberaceae 1), dan staat onomstootelijk vast dat de doode een juiste verklaring heeft afgelegd. Worden echter de bladeren van een gewonen heester vertoond, dan is dit het bewijs dat onwaarheid is gesproken. In dat geval wordt aangenomen, dat een booze geest het antwoord heeft gegeven. Onder helsch lawaai der trommen wordt de doode naar de hut waar hij opgebaard is teruggebracht en aldaar, met het doel den boozen geest te verdrijven, het geraas tot een voor Europeesche ooren onuitstaanbaar lawaai opgevoerd. Soms wordt het lijk nog eens denzelfden dag ondervraagd, meestal heeft dit echter eerst den volgenden dag plaats.

In het bijzonder wanneer de vragen met de bedoeling gesteld worden door het antwoord een bepaalde persoon of groep te begunstigen en daarmede andere leden van den stam niet accoord gaan, kan de comedie soms gedurende weken voortgang hebben.

Het bestek van dit opstel gedoogt niet dieper op de voorstellingen en de gebruiken der Boschnegers in te gaan en wij zullen den draad van het verhaal weer opvatten.

Jankosoe, de overleden Granman der Saramaccanen, was in 1898 op slinksche wijze Grootopperhoofd geworden en gedurende 34 jaren het zinnebeeld van de onafhankelijkheid van den stam geweest. Slechts als zoodanig genoot hij, uitgezonderd bij zijn clan, aanzien bij den stam; van de uitoefening van gezag is gedurende deze periode in het geheel geen sprake geweest. Schrijver moest hem in 1924 dwingen ten minste eens aan de Zending van Ganzee, het grootste boschnegerdorp der Saramaccanen, aan te leggen. Geen enkel ander dorp, waarin de opperhoofden der overige tien onderstammen wonen, heeft hij ooit bezocht. De dood van Jankosoe werd dan ook, behalve door de leden van zijn eigen onderstam, in het geheel niet betreurd; slechts de vrees,

$\left.{ }^{1}\right)$ De Boschnegers noemen het blad mai embe embe, een Afrikaansch woord, dat vertaald moet luiden: ik spreek de waarheid. 
door het niet naleven der gebruiken magisch gevaar voor de samenleving te verwekken, dwong tot uiterlijk rouwbetoon. Door dit laatste werd buitendien aan het economische leven ernstige schade berokkend. Jankosoe stierf gedurende den tijd van het beplanten der kostgronden en dien gedurende welken de houtaankap in vollen gang is. $\mathrm{Nu}$ wil het gebruik, dat gedurende de periode dat het lijk van het Grootopperhoofd boven aarde wordt gehouden, de leden van den stam in hun dorpen moeten vertoeven. Zoowel de kostgronden, als ook het bosch waarin het hout wordt bekapt, dat gedurende de hooge waterstanden moet worden afgevoerd, liggen meestal ver van deze dorpen af en daar de goede gang van zaken een verblijf op deze plaatsen voor korter of langer tijd eischt, geraakte in 1932 zoowel de voedselvoorziening als ook het hoofdinkomen van den Boschneger, de houtkap, in ernstig gevaar.

Het lijk van Jankosoe werd nagenoeg twee maanden onbegraven gelaten. Zooals reeds in den aanhef werd gezegd, moet de voornaamste oorzaak voor het gesol met het cadaver van den Granman in de weigering van den doode worden gezocht een opvolger aan te wijzen. De lezer die meer van de kwestie van opvolging der Grootopperhoofden bij de Saramaccanen wil weten wordt naar twee artikelen in dit tijdschrift, getiteld Het einde van een dynastie en Een Staat in den Staat, van 1932 verwezen. Voor anderen zullen wij op beknopte wijze een stuk geschiedenis moeten ophalen.

In het vredesverdrag met den stam werd bepaald, dat bij overlijden van een Grootopperhoofd de elf opperhoofden der onderstammen vergaderen en uit hun midden een nieuwen Granman kiezen. In het jaar 1835 werd een vermoedelijk op deze wijze gekozen en door het bestuur der kolonie benoemde granman van den onderstam der Nassynegers, Koffie Bosman genaamd, door het bestuur wegens een overtreding van het vredesverdrag naar Post Gelderland ter verantwoording geroepen. Door de ambtenaren schuldig bevonden werd Koffie Bosman uit zijn waardigheid ontzet. Een van de vrouwen van dezen Granman behoorde tot den onderstam der Matjau negers; zij droeg den naam van Jaja. Intrigant en heerschzuchtig van karakter had zij slechts één doel voor oogen: aan haar onderstam en meer speciaal aan haar clan, de zoogenaamde Tatainegers, het Granmanschap te verzekeren. Tatai wil zeggen touw; de overlevering wilde n.m. dat haar voorouders door middel van een touw uit den hemel naar de aarde zijn afgeklommen. Met behulp van toovermiddelen 
verwarde Jaja het inzicht der blanken die op Gelderland over Koffie Bosman moesten oordeelen. Haar zoon Wittiwojo werd dan ook door de afgezanten van den Gouverneur der Kolonie als opvolger van zijn vader benoemd. Dit was niet slechts in tegenspraak met de bepalingen van het vredesverdrag, doch voornamelijk een aanranding der instelling van het moederrecht. Volgens het matriarchaat, de ongeschreven wet der Boschnegers, kan een zoon niet van zijn vader erven, staat de laatste als geheel vreemde buiten het familieverband.

Een andere opvatting der Boschnegers wil, dat een Granman voor zijn leven is benoemd, niet ontzet kan worden. Door de benoeming van Wittiwojo ontstond dus een voor de Boschnegers onaanvaardbare toestand. Aan deze situatie maakte volgens de overlevering Jaja een einde, door Koffie Bosman, wien de Saramaccanen nog altijd als Granman eerbiedigden, uit den weg te ruimen. Toen hij naar de oorzaak van zijn dood werd ondervraagd, verklaarde hij door de Matjaunegers om het leven te zijn gebracht en zoodoende ontstond voor de Grootopperhoofden van den onderstam der Matjau een Koenoe. Hieronder verstaat men den vloek die, als geheimzinnige macht gepersonifieerd, als wreker optreedt. Hij treft echter den veronderstelden misdadiger niet direct; integendeel om dezen zooveel mogelijk leed te berokkenen, spaart hij dezen en doodt met verfijnde wreedheid een voor een zijn naastbestaanden, de leden van zijn bere, d.i. de familieleden die van een gemeenschappelijke stammoeder afstammen. De Koenoe kiest een levende tot den uitvoerder van zijn wil. De wenschen van dezen moeten onvoorwaardelijk vervuld worden; zoodoende gaat een groot gedeelte van de toelage die het Grootopperhoofd van het Gouvernement geniet in de handen van de persoon over die tijdelijk drager van den Koenoe van Koffie Bosman is. Een treffend staaltje van de macht van den Koenoe levert de volgende geschiedenis. In het jaar 1923 werd Granman Jankosoe door den Gouverneur ontboden. Kort te voren had ik met den Granman een voorloopige overeenkomst betreffende de verbetering van de economische toestanden gesloten en hij was toen verlangend deze te Paramaribo te bekrachtigen. Jankosoe kwam echter niet opdagen en toen een tweede en derde oproeping evenmin effect hadden, besloot de Gouverneur, die verzet veronderstelde, gewapend in te grijpen. Het is echter geen onwil doch onmacht geweest die den Granman verhinderde aan de oproeping van den landvoogd gevolg te geven. De Koenoe van Koffie Bosman had aan Jankosoe verboden naar Paramaribo 
te reizen en eerst toen een militaire patrouille een gedeelte van het boschnegergebied had bezet, liet zich de Koenoe vermurwen om de toestemming tot de reis naar Paramaribo te verleenen.

De ochtendkoelte dreef een ijle rook uit een van de hutten te Granmankondre, den zetel van het Grootopperhoofd der Saramaccanen aan den Pikienrio. De scherpe geur van smeulend hout was doormengd met den reuk die onmiddellijk aan een barbakot deed denken 1 ).

Temeer als men weet dat de Boschnegers aan vleesch dat nagenoeg in staat van ontbinding verkeert de voorkeur boven versch vleesch geven en daarom hun barbakotten een geur verspreiden welke slechts als stank omschreven kan worden.

In de hut, uit welke deze stank ons met de ochtendbries tegenwoei, stond inderdaad een barbakot. Daarop lag, vastgebonden op een door den rook zwart geworden plank, lang en spichtig in een door de voortdurende berooking donkerbruin geworden omhulsel, wat eens de herculische gedaante van den Granman Jan Kosoe was geweest. Ofschoon het reeds de tweeenveertigste dag na zijn overlijden was, gunde men hem de rust in de koele aarde nog niet. Onmededoogend egoïsme, misdadige, in het gewaad van primitieve voorstellingen gestoken voornemens en bovenzinnelijke terreur, hielden aan de obscure baar de wacht. Ten koste van wat ook wilden de negers van den Pikienrio in het bezit van het Granmanschap blijven. En hierover moest de doode op den barbakot beslissen.

De sluwe negers wisten dat Jankosoe geen opvolger kon aanwijzen, die aan de eischen welke de instelling van het matriarchaat stelt kon voldoen. De Koenoe had onder de clan der Tatainegers grondige opruiming gehouden. Jankosoe was de laatste tak van den stamboom; hij had zwaar geboet voor de heerschzucht van zijn stammoeder Jaja. De schokken welke deze primitieve gedurende zijn leven had te doorstaan gehad, zouden voor menig Westersch brein veel vroeger noodlottig zijn geworden. Toen hij het vergif ter hand nam deed Jankosoe dit welbewust en met het doel de kinderen, door hem bij vrouwen van andere onderstammen verwekt, te beschermen tegen den Koenoe,

1) Een barbakot is een uit stokken samengestelde stellage, waarop boven een smeulend houtvuur de opbrengst van jacht of vischvangst wordt gedroogd, of beter gezegd, wordt geroosterd, teneinde deze tegen bederf te vrijwaren.

West-Indische Gids XXVIII 
die reeds zijn greep tot hen uitstrekte, nu er geen bloedverwanten meer over waren, volgens de opvattingen der Boschnegers als slachtoffers in aanmerking komend.

Terwijl het geraas der trommen de lucht vervulde en de adepten der Obia de fetischen welke de toegangen tot het dorp beschermden, een extra beurt gaven, zaten bij den Grangadopau de hoofden van den stam en de ouden van dagen, teneinde de Gransembe, de geesten van hun voorouders welke als bemiddelaars bij den Grangado optreden, te smeeken heden aan Jankosoe het juiste inzicht te willen verleenen om eindelijk een opvolger aan te wijzen.

Bij de oudere hoofden - buiten hen die, als Jankosoe zelf, tot den onderstam der Matjau behoorden - heerschte de meening, dat, nu het volstrekt vaststond dat voor een aanwijzing volgens de instelling van het moederrecht geen Matjauneger in aanmerking kon komen, Jankosoe tot de overlevering zou terugkeeren. Er waren Grootopperhoofden uit de onderstammen der Loango, der Nassynegers en van de Awana geweest. Van al deze groepen waren rechthebbenden, erfgenamen van den stok der eerste opperhoofden, als pretendenten voor het Granmanschap in leven. Op de vergadering bij den Grangadopau deed zich in het bijzonder het hoofd der Loango gelden. De Obia der Loango, een uit Afrika medegebrachte fetisch, welke te Abeniedatra, een aan den Gran Rio gelegen dorp, in eere wordt gehouden, had zelfs een ultimatum gesteld: heden nog zou een beslissing genomen moeten worden. Alle vergaderden kwamen onder den indruk hiervan en toen zij opstonden en zich met hun zitbankjes onder den arm in plechtigen stoet naar de plaats begaven waar Jankosoe voor het laatst ondervraagd zou worden, was op de gezichten van velen hunner de sombere uitdrukking verdwenen, te voren onder den Grangadopau vertoond.

Langzaam, statig, kwamen de dragers met het lijk op hun hoofden aanstappen, om op ongeveer tien passen afstands van het oude hoofd, die in zijn veelkleurig grankrosi gehuld als een bont stambeeld, op ongeveer evenveel passen voor de menigte stond, halt te houden. De plotseling ingetreden diepe stilte, welke als een nachtmerrie op de aanwezigen neerdaalde, werd eerst na eenige minuten door herhaald kuchen van het oude hoofd verbroken. De stilte werd nog intenser; met ingehouden adem luisterde iedereen naar de eerste vraag die de oude man stelde. Gevraagd werd of de erfgenaam van zijn stammoeder Bossi, een van de twee zusters van den eersten door het Gouvernement in 
1761 benoemden Granman, een Awananeger, als Grootopperhoofd in aanmerking kwam. Alles keek naar den voorsten drager en toen deze ontkennend het hoofd schudde, kon hier en daar in de menigte beweging bespeurd worden. Aan deze enkelingen werd echter geen tijd gelaten om zich aan hun emotie over te geven; een tweede vraag volgde en op deze nog vele andere. Telkens werden personen genoemd, die òf vermeenden rechthebbenden op den titel te zijn, òf bij den stam aanzien genoten. Op alle vragen werd door Jankosoe ontkennend geantwoord. Eindelijk kwam het tot de inleiding van den coup d'état, dien de sluwe negers van den Pikien Rio meesterlijk voorbereid hadden. Gevraagd werd of een zekere Atoedentoe, een aanverwant van den vader van Jankosoe, Granman zou moeten worden. Tot groote ontsteltenis van velen in de menigte werd deze vraag, door knikken met het hoofd van den voorsten drager, bevestigend beantwoord. De teerling was geworpen, de terreur bestendigd.

De uitverkorene was de lijfarts en eenigste vertrouweling van Jankosoe geweest. Hij behoorde niet tot de clan der Tatainegers, kon daarom geen rechten geldend maken en was ook geen hoofd bij den onderstam. Atoedentoe was bij den geheelen stam om zijn valschheid en doortrapte geslepenheid veracht, hetgeen hem ook zijn naam bezorgde, die vertaald dubbelhartig of huichelaar beteekent.

Ofschoon de geheele stam het daarmede eens was, dat Atoedentoe de laatste persoon was, die in aanmerking mocht komen, kwam niemand tegen de zoogenaamde uitspraak van het cadaver van Jankosoe in verzet. De magische invloed welke van deze handeling uitging overheerschte alle gevoelens van recht en billijkheid, drong alle aspiraties der overige onderstammen naar den achtergrond en noopte tot uitstel, hetgeen beteekende, dat door de aanwijzing van Atoedentoe tot Grootopperhoofd nieuwe banen voor den Koenoe, alias moord en terreur, geopend werden.

Alvorens wij tot de bespreking der houding, welke het bestuur der Kolonie in deze aangelegenheid heeft aangenomen, overgaan, zullen wij vooraf eenige regels aan dingen van meer ethnologischen aard wijden. Na de aanwijzing van een opvolger bleef het lijk nog twee weken onbegraven. De redenen voor dit uitstel moeten niet in politieke doch in zuiver psychische omstandigheden gezocht worden, waarbij de inachtneming der gebruiken de voornaamste rol speelt. Ieder overleden persoon, met uitzondering van degenen die accidenteel om het leven komen, wordt in een kist begraven. Materiaal tot het vervaardigen der 
doodkisten mag echter niet in voorraad worden gehouden. Het voornaamste zijn de planken. Volgens de opvattingen lokken planken die voor het vervaardigen van doodkisten gereed worden gehouden, den dood aan. Zou een neger er toe overgaan hout voor dit doel te bewerken en op te slaan, dan zou men hem ervan betichten de gemeenschap in gevaar te brengen, de bedoeling te hebben, ongewenschte dorpsgenooten uit den weg te ruimen.

De doodkist wordt eerst vervaardigd wanneer de betreffende doode ondervraagd is en in staat wordt geacht de reis naar de verblijfplaats der voorouders te aanvaarden. Dan eerst wordt de boom geveld die de planken moet leveren. Met den bijl worden eerst dikke platen uit den stam gehouwen en deze met het kapmes tot planken bewerkt. Met deze wijze van werken gaat veel tijd verloren, in het bijzonder wanneer aan het uiterlijk der doodkist grootere zorg moet besteed worden. Ik heb doodkisten gezien waarvan de planken van kunstig snijwerk waren voorzien en met koperen platkopspijkers waren versierd. Eigenaardig was dat de ornamentiek geheel en al het kruismotief volgde.

Zijn de overblijfselen van den doode ten slotte in de kist geborgen, dan gaat men over tot het delven van het graf. Voor vrouwen en kinderen en voor negers van gering aanzien, wordt met een gewoon gat volstaan. Voor hoofden echter wordt de bakoe gedolven. Eerst wordt een drie à vier meters groot vierkant gat, dat vier à vijf voeten diep is, uitgegraven. In een der vier zijwanden wordt daarna een ruimte uitgehold, groot genoeg om de doodkist op te nemen. Deze wordt tot op den bodem van het groote gat neergelaten en daarna in het hol van den zijwand geschoven. Met het bloed van een in het gat geslacht en daarin achtergelaten haan, wordt het graf verzegeld. Eventueele booze geesten die nog kans gezien mochten hebben van den doode bezit te nemen, worden door deze handeling ten eeuwigen dage in het graf opgesloten, terwijl de Granjorka van den overledene de reis naar de plaats aanvaardt waar de Gransembe van den stam, de heiligen, vergaderd zijn.

Het bestek van dit opstel gedoogt niet, nader op de talrijke lijkgebruiken der Boschnegers in te gaan, omdat het niet in de bedoeling ligt een ethnologische schets te geven, doch om het bestuursbeleid in zake de benoeming van een Grootopperhoofd te schetsen.

Het Grootopperhoofd Jankosoe was in Februari 1932 overleden en gedurende de laatste dagen van de maand Maart werd op de boven beschreven wijze een nieuwe Granman aangewezen. De 
negers uit den Pikien Rio haastten zich echter geenszins hiervan ter Gouvernementssecretarie te Paramaribo kennis te geven. Men vreesde het onderzoek naar de geldigheid van deze aanwijzing. Bij de benoeming van Jankosoe had men niet naar de aanwijzing van dezen door het Grootopperhoofd Wittiwojo gevorscht; men had te Paramaribo echter het vertoon van den stok van een opperhoofd geëischt, wiens nakomelingen aanspraak op het Granmanschap konden maken. Omdat de negers uit den Pikien Rio aan dezen eisch niet konden voldoen namen zij hun toevlucht tot bedrog. Men gaf voor den stok niet mede naar de stad genomen te hebben, doch deze zou met grooten spoed worden gehaald. De benoeming van Jankosoe werd toen uitgesteld en had eerst plaats op vertoon van den eersten stok die in 1761 door het toenmalige bestuur aan een opperhoofd was uitgegeven. Dit opperhoofd der Awananegers, Arabie, werd ook als eerst Grootopperhoofd bij de Saramaccanen benoemd. De boodschappers der sluwe Matjaunegers deelden n.m. aan den houder van den stok, den kapitein Nicodemus te Aurora, mede, dat de Gouverneur den ouden stok gaarne eens wilde zien. Het bedrog is later uitgekomen; de vrees echter voor het magische gevaar aan de aanranding van het Granmanschap verbonden, heeft aan ieder Boschneger het zwijgen opgelegd.

Atoedentoe wist dat hij den geheelen stam tegen zich had en dat hij, zoo het tot een open uitspraak zou komen, weinig kans zou maken om officieel als Granman te worden benoemd. Daar kwam hem het bestuur der Kolonie onverwacht te hulp. Te Paramaribo waren allerlei geruchten over een nieuw aangewezen Granman doorgedrongen en toen deze in het najaar 1932 maar niet opdaagde, werd een ambtenaar naar de Boven Suriname gezonden, teneinde een onderzoek naar de redenen van het interregnum in te stellen. Deze ambtenaar was de taal der Saramaccanen niet machtig en volkomen onbekend met de instellingen, de gebruiken en opvattingen der negers. Atoedentoe had daarom licht spel en de ambtenaar keerde dan ook met de voordracht tot zijn aanstelling naar Paramaribo terug. Conform dit voorstel werd de aanwijzing, door Jankosoe, op den 42sten dag na zijn overlijden gedaan, officieel bevestigd.

Naschrift.

Door den voorganger van den Gouverneur, die Atoedentoe tot Grootopperhoofd heeft doen benoemen, was bij den stam der Saramaccanen, met het doel dezen nauwer bij het economische 
leven der Kolonie aan te sluiten, politiek ingegrepen. Hiervan getuigen de Gouvernementsresolutiën van 9 Maart 1923 no. 818 en van 5 April 1924 no. 1101. In het bijzonder achtte deze bewindsman het gewenscht, dat de Grootopperhoofden van den stam hun standplaats aan de Middenrivier zouden kiezen.

Teneinde een goed overzicht der samenleving in het boschland der Surinamerivier te verkrijgen, werd aan een opzichter van het Boschwezen opgedragen den stam der Saramaccanen zoo goed als dit mogelijk was te registreeren. Aan deze opdracht werd voldaan. Het register, waarvan ook afschriften aan andere departementen werden toegezonden, werd ter Gouvernementssecretarie gedeponeerd. Daarin werd ook de opvolging der Grootopperhoofden uitvoerig behandeld. Had men de in het register gegeven wenken in overweging genomen, dan zou bij het overlijden van Jankosoe het primitieve gedoe uitgeschakeld en bij de Saramaccanen een dragelijker toestand in het leven geroepen kunnen zijn. Het doet dan ook eigenaardig aan, dat - thans - met het oog op den toekomstigen politieken status van Suriname - Atoedentoe door een officieele commissie naar zijn meening dienaangaande gevraagd werd.

Paramaribo 20 October 1946. 